\title{
INVESTIGATION OF THE INFLUENCE OF PRODUCT VARIETY ON INVENTORIES
}

pages: $34-44$ IN HOSPITALS

\author{
Agaraoli AravazhI* (i) Berit Irene Helgheim \\ BJØRN JAEGER
}

\begin{abstract}
A B S T R A C T
The literature on product variety provides great insights into various businesses. However, little research has been conducted on product variety in the healthcare industry. This study aims to explore the influence of product variety on inventory in hospitals. Since most hospitals are known to replenish products using a homegrown ad-hoc system, a model is developed for exploring all possible product combinations and substitutions. This article presents the behaviour of product substitution, which may be either one-to-one or many-to-one for both sterile and non-sterile products, in the hospital with cost factors. It discusses the product variety reduction and its corresponding cost impacts. The data on a hospital inventory over the course of six years has been procured from a hospital in Norway. Based on the results, the hospital could have a potential product variety reduction of approximately $11 \%$ and cost savings from the spending of approximately NOK 3.6 million. Reducing the variety of products in hospital inventories proves to be an approach to reducing costs. The model developed for the research is universal in nature and could be used in other fields, such as retail, marketing etc.
\end{abstract}

KEY WORDS

product variety, inventory management, substitution effect, hospitals

10.2478/emj-2020-0003
Agaraoli Aravazhi

Molde University College - Specialised University in Logistics, Norway ORCID 0000-0001-6489-0768

*Corresponding author: e-mail: Agaraoli.Aravazhi@himolde.no

Berit Irene Helgheim

Molde University College - Specialised University in Logistics, Norway ORCID 0000-0003-1600-7867

Bjørn Jæger

Molde University College - Specialised University in Logistics, Norway ORCID 0000-0002-4661-5102

\section{INTRODUCTION}

Hospitals are known to use many products. The hospital staff responsible for managing products are constantly handling supply shortages and other logistical problems and challenges (Tucker \& Edmondson, 2003).
To avoid supply shortages and improve cost control, many studies focused on optimising hospital inventory. Examples of such studies can be seen in the work by Varghese, Rossetti, Pohl, Apras, and Marek (2012) and Kritchanchai and Meesamut (2015). The

Citation: Aravazhi, A., Helgheim, B. I., \& Jæger, B. (2020). Investigation of the influence of product variety on inventories in hospitals. Engineering Management in Production and Services, 12(1), 34-44. doi: 10.2478/emj-2020-0003 
latter identified potential cost savings of $14 \%$. Besides this research on savings, it was found that proper hospital logistics handling helps to improve job satisfaction among the nursing staff (Landry \& Beaulieu, 2013). One possible way to improve logistics performance is to reduce the number of products used in hospitals (Wan et al., 2012). This idea could be further elaborated considering the product variety, i.e., the range of products within a given group.

It is up to the medical staff to determine the demand for various devices as well as single-use medical products. However, not many (if any) among the medical staff have training in inventory handling. In general, their experience is that the available equipment is essential. Therefore, they tend to overestimate the need for the equipment based on an "in case of" strategy. For single-use products, such as bandages and compresses, one may discuss how many sizes and what kinds are necessary without having an impact on the quality of performed medical procedures.

The relevant question is whether there is a need for all sizes and types within a given product group. For example, for one type of bandages, a hospital may use five sizes. The largest and smallest of these may be used only once a year, resulting in waste due to the expiry date. Instead of having all sizes, one may substitute a smaller-size product with a large-size product, for example, a large bandage can be used on a smaller injury. This way, it is possible to substitute large and small bandages.

Current research (including the studies mentioned earlier) does not address these issues of product groups and product variety to the needed extent. This paper proposes a substitution method and investigates the effect on cost made by the substitution of an item with a similar item within a product group. The data used in this paper was collected from a rural hospital in Norway.

This paper is organised as follows. Section 1 provides a review of the literature on inventory management and product variety. Section 2 describes the data used in the research. Section 3 describes the substitution model developed for this study. Section 4 presents the results, which are further discussed in Section 5. Finally, the concluding comments and possible future research directions are presented.

\section{LITERATURE REVIEW}

In general, hospitals are complex organisations that consist of various units, including those that provide various medical services to patients and those that are non-medical, such as administration, housekeeping etc. Each of these units performs distinctive functions, which require unique products. Thus, a hospital must maintain a considerable inventory, which results in high expenditures. Many studies indicate hospitals spending $25 \%$ to $30 \%$ of their budget on purchasing and handling the inventory (Ozcan, 2005).

Several inventory management methods have been developed for the reduction of costs and streamlining the inventory distribution process. Inventory optimisation is one of the most common methods to ensure the cost-effective management of inventory. The researchers Varghese et al. (2012) presented a case study for optimising inventory with the help of the $\mathrm{r}, \mathrm{Q}$ inventory policy, based on which an order of $\mathrm{Q}$ quantities is placed for each $\mathrm{r}$ period. In this study, the authors found potential savings amounting to $14 \%$ from inventory present in the hospital's distribution centre. Similar savings were identified in the study conducted by Kritchanchai and Meesamut (2015). The authors developed an inventory planning model for "A" class products (high consumption) involving various inventory policies. In addition, the research pointed out the reduction of product shortage by $92.98 \%$. One of the benefits of proper inventory management is the reduction of the inventory value present in the system. The authors Rachmania and Basri (2013) demonstrated a 50\% reduction in the inventory value of oncology medications at a public hospital in Indonesia by using the $s$, $\mathrm{Q}$ policy, based on which an order of Q quantities is placed when the current stock level reaches s quantities.

The nature of hospital logistics is complex and multi-faceted. The propriety of managing the operations may benefit from exploring and adopting policies from logistics in other sectors. One such policy is the consideration of the product variety, which significantly impacts organisations in terms of profits and various supply-chain parameters. The research conducted by Wan et al. (2012) showed the importance of careful planning in terms of the level of product variety for organisations. The authors looked into a soft drink bottler with 108 distribution centres and found that the product variety had a direct negative effect on the fill rate of products, whereas the product sales were affected both directly and indirectly by the product variety. As product variety increases, the product sales initially increase as well, and after a certain point, the sales fall. 
The product must be understood before making changes in the product variety at hospitals. One of the most straightforward approaches is the product hierarchy method proposed by (Malone, 1987). This approach was also used in the research by Fujita, Sakaguchi, and Akagi (1999) for product design and development, and in the article by Wang et al. (2011) for product manufacturing. These studies used a product hierarchy of three levels. The top level was comprised of the product family, which was followed by the product group or module, and finally, the product or module variants.

Erens and Verhulst (1997) mapped products based on the required function, technological realisation, and physical realisation. Fujita et al. (1999) used a similar concept; however, they defined the customer, function, and manufacturing viewpoints. The authors employed a binary integer programming model together with a specialised algorithm for the optimisation of the product variety. This research was performed in a company that designed television receiver circuits.

In several other studies, the issue of product variety was addressed with the help of the $0-1$ integer programming approach. In the context of manufacturing, Wang et al. (2011) developed an optimisation problem to explore trade-offs between the product variety and the manufacturing complexity in the design of a mixed-model assembly system. The decision-making complexity of this research was related to the selection of best product variants to be manufactured on the assembly line considering various costs associated with their production. The main requirement for the optimisation of the product variance was to achieve the highest customer market share. Similar work was also conducted by Nishino, Takenaka, Koshiba, and Kodama (2014); however, this research dealt with the service industry.

Several researchers demonstrated the use of integer programming for product variety problems in the retail sector. In the work of McBride and Zufryden (1988), the product variety reduction was made based on customer preference. Borin, Farris, and Freeland (1994) came up with a decision-making framework based on the assortment and space allocation for products. Jayaraman, Srivastava, and Benton (1998) developed a non-linear optimisation model for the product variety, also considering inventory and product brands. The authors concluded that as the budget increased, the product variety could also be increased for achieving the desired profit for the retailer.
To sum up, the research in the areas of logistics for such contexts as manufacturing and retail has clearly demonstrated the benefits of carefully considered product variety. However, the area of hospital inventory management has not yet seen an in-depth study on the product variety. Therefore, the research presented in this paper aims to explore the reduction in the product variety combined with the inventory optimisation using a brute force analysis. The developed model and the results presented further contribute to the understanding of the effect made by the product variety and possible product substitutions on the inventory costs of hospitals.

\section{RESEARCH DATA}

The data was collected in a small rural hospital in Norway. The external order data for the duration of six years (2010-2015) was taken from the central database of the hospital. Each year, the hospital makes more than 6000 external orders for a total of 2331 products, of which 1645 are sterile, and 686 are nonsterile. Currently, the hospital uses a two-level product hierarchy. The products are classified into ten product families, such as laboratory supplies, medical disposables, office supplies etc.

As defined in the literature, the product architecture, includes at least three levels, namely, the product family, the product group, and the product (Fujita et al., 1999). With the help of product mapping, an intermediate level was defined and named product groups, based on the function of the product. These product groups contained products which differed only by characteristics. In total, 1481 product groups of sterile products and 532 product groups of nonsterile products were created. The values of product substitution factors used further in the model were defined manually based on product attributes such as size and quantity. Currently, the hospital does not optimise its inventory management. The model, which is developed and proposed further, addresses the issue of product variety and inventory optimisation.

\section{SUBSTITUTION MODELLING}

Since the hospital uses a two-level hierarchy system for products, the authors of this article developed an intermediate level and called it "the product 
group." This level will help the study into the product variety as it is intended for products which are used for the same purpose but differ based on their characteristics. For example, assume a hospital uses blister adhesive bandages of two different pack sizes 6 and 12 , which belong in the product family of medical consumables. Therefore, in the product analysis, these two products can belong to a single group. Here, the quantity required for the substitution of one product with another varies; this can be termed many-to-one substitution. This many-to-one substitution makes it difficult to understand the effect of the product variety at hospitals. To understand this effect, the substitution model was developed and presented. This substitution model uses notations provided in Table 1.

A product group consists of $\mathrm{N}$ products, which creates $2^{N}$ possible ways to use products within this product group. This is similar to the $2 \mathrm{k}$ factorial design, which is commonly mentioned in the literature on the design of experiments (Sanchez, 2005). Table 2 represents the product selection for a product group of three products.

A simple condition in product usage is that at least one product in a product group must be used for each design point. The equation (1) represents this rule.

$$
\sum_{i=1}^{N} U_{i}^{p} \geq 1
$$

Therefore, product usage number 0 becomes invalid. Thus, this reduces the number of possibilities from eight to seven. Therefore, the number of possibilities for a product group with $\mathrm{N}$ products is $2^{N}-1$.

Tab. 2. Product usage for a product group containing three products

\begin{tabular}{|c|c|c|c|}
\hline $\begin{array}{c}\text { PRODUCT } \\
\text { USAGE NUMBER }\end{array}$ & $\mathbf{U}_{\mathbf{1}}$ & $\mathbf{U}_{\mathbf{2}}$ & $\mathbf{U}_{\mathbf{3}}$ \\
\hline 0 & 0 & 0 & 0 \\
\hline 1 & 1 & 0 & 0 \\
\hline 2 & 0 & 1 & 0 \\
\hline 3 & 1 & 1 & 0 \\
\hline 4 & 0 & 0 & 1 \\
\hline 5 & 1 & 0 & 1 \\
\hline 6 & 0 & 1 & 1 \\
\hline 7 & 1 & 1 & 1 \\
\hline
\end{tabular}

\subsection{ESTIMATED PRODUCT SUBSTITUTION}

For most of the product usage numbers, there are one or more unused products. In these instances, their demand must be substituted for by another product. Therefore, irrespective of whether a product can substitute for another product, demand substitution is done. For simplification purposes, a simple rule applies that only one product can be used to substitute for another product for a design point and, thus, invalidates the partial substitutions. Therefore, the number of substitutions is equal to the number

Tab. 1. Notations used in the substitution model

\begin{tabular}{|c|c|}
\hline NOTATION & DESCRIPTION \\
\hline$N$ & Total number of products within the product group \\
\hline$i, j$ & Product number within the product group; $i, j \in(1, \ldots, N)$ \\
\hline$p$ & Notation used for product usage number \\
\hline$M$ & Notation used for the design point \\
\hline$U_{i}^{p}$ & $\begin{cases}1, & \text { if product } i \text { within the product group is used in the product usage number } \\
0, & \text { Otherwise }\end{cases}$ \\
\hline$U_{i}^{M}$ & $\begin{cases}1, & \text { if product } i \text { within the product group is used in the design point } M \\
0, & \text { Otherwise }\end{cases}$ \\
\hline$U_{j}^{M}$ & $\begin{cases}1, & \text { if product } j \text { within the product group is used in the design point } M \\
0, & \text { Otherwise }\end{cases}$ \\
\hline$W_{j i}^{M}$ & $\begin{cases}1, & \text { if product } j \text { within the product group is used in the design point } M \text { where } U_{j}^{M} \\
0, & \text { Otherwise }\end{cases}$ \\
\hline$S_{i j}^{M}$ & 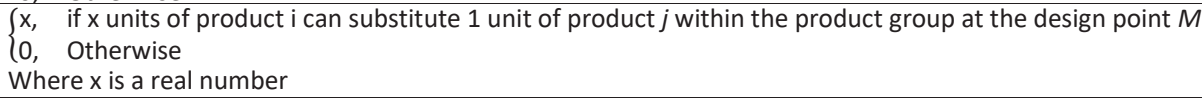 \\
\hline$R_{i j}^{M}$ & $\begin{cases}1, & \text { if } S_{i j}^{M} \neq 0 \\
0, & \text { if } S_{i j}^{M}=0\end{cases}$ \\
\hline$I D_{i}$ & Initial demand of product $i$ within the product group \\
\hline$C D_{i}^{M}$ & Modified demand of product $i$ within the product group at the design point $M$ with the replacement factor \\
\hline$D_{i}^{M}$ & Modified demand of product $i$ within the product group at the design point $M$ with the conversion factor \\
\hline$L C_{i}^{M}$ & Logistics cost of product $i$ within the product group at the design point $M$ \\
\hline$T C_{i}^{M}$ & Total cost of product $i$ within the product group at the design point $M$ \\
\hline$L C^{M}$ & Summation of logistics cost of products in the product group at the design point $M$ \\
\hline$T C^{M}$ & Summation of the total cost of products in the product group at the design point $M$ \\
\hline
\end{tabular}




$$
\begin{gathered}
\sum_{i=1}^{N} W_{j i}^{M}=1, \forall j: U_{j}^{M}=0 \\
\sum_{i=1}^{N} \sum_{j=1}^{N} W_{j i}^{M}=N-\sum_{i=1}^{N} U_{i}^{M} \\
\text { Number of design points }=\left(\sum_{i=1}^{N} U_{i}^{M}\right)^{N-\sum_{i=1}^{N} U_{i}^{M}}
\end{gathered}
$$

Tab. 3. Number of possible product usage and design points based on size of product groups

\begin{tabular}{|c|c|c|c|c|c|c|}
\hline $\begin{array}{l}\text { DESIGN } \\
\text { POINTS }\end{array}$ & $U_{1}$ & $U_{2}$ & $\mathbf{U}_{3}$ & $W_{1}$ & $W_{21}$ & $W_{3 \jmath}$ \\
\hline \multirow[t]{3}{*}{1,1} & \multirow[t]{3}{*}{1} & \multirow[t]{3}{*}{0} & \multirow[t]{3}{*}{0} & 0 & 0 & 0 \\
\hline & & & & 1 & 0 & 0 \\
\hline & & & & 1 & 0 & 0 \\
\hline \multirow[t]{3}{*}{2,1} & \multirow[t]{3}{*}{0} & \multirow[t]{3}{*}{1} & \multirow[t]{3}{*}{0} & 0 & 1 & 0 \\
\hline & & & & 0 & 0 & 0 \\
\hline & & & & 0 & 1 & 0 \\
\hline \multirow[t]{3}{*}{3,1} & \multirow[t]{3}{*}{1} & \multirow[t]{3}{*}{1} & \multirow[t]{3}{*}{0} & 0 & 0 & 0 \\
\hline & & & & 0 & 0 & 0 \\
\hline & & & & 1 & 0 & 0 \\
\hline \multirow[t]{3}{*}{3,2} & \multirow[t]{3}{*}{1} & \multirow[t]{3}{*}{1} & \multirow[t]{3}{*}{0} & 0 & 0 & 0 \\
\hline & & & & 0 & 0 & 0 \\
\hline & & & & 0 & 1 & 0 \\
\hline \multirow[t]{3}{*}{4,1} & \multirow[t]{3}{*}{0} & \multirow[t]{3}{*}{0} & \multirow[t]{3}{*}{1} & 0 & 0 & 1 \\
\hline & & & & 0 & 0 & 1 \\
\hline & & & & 0 & 0 & 0 \\
\hline \multirow[t]{3}{*}{5,1} & \multirow[t]{3}{*}{1} & \multirow[t]{3}{*}{0} & \multirow[t]{3}{*}{1} & 0 & 0 & 0 \\
\hline & & & & 1 & 0 & 0 \\
\hline & & & & 0 & 0 & 0 \\
\hline \multirow[t]{3}{*}{5,2} & \multirow[t]{3}{*}{1} & \multirow[t]{3}{*}{0} & \multirow[t]{3}{*}{1} & 0 & 0 & 0 \\
\hline & & & & 0 & 0 & 1 \\
\hline & & & & 0 & 0 & 0 \\
\hline \multirow[t]{3}{*}{6,1} & \multirow[t]{3}{*}{0} & 1 & 1 & 0 & 1 & 0 \\
\hline & & & & 0 & 0 & 0 \\
\hline & & & & 0 & 0 & 0 \\
\hline 6,2 & 0 & 1 & 1 & 0 & 0 & 1 \\
\hline & & & & 0 & 0 & 0 \\
\hline & & & & 0 & 0 & 0 \\
\hline 7,1 & 1 & 1 & 1 & 0 & 0 & 0 \\
\hline & & & & 0 & 0 & 0 \\
\hline & & & & 0 & 0 & 0 \\
\hline
\end{tabular}

\begin{tabular}{|c|c|c|}
\hline $\begin{array}{c}\text { SIZE OF PRODUCT } \\
\text { GROUP }\end{array}$ & $\begin{array}{c}\text { No. OF POSSIBLE } \\
\text { PRODUCT USAGE }\end{array}$ & $\begin{array}{c}\text { No. OF DESIGN } \\
\text { POINTS }\end{array}$ \\
\hline 1 & 1 & 1 \\
\hline 2 & 3 & 3 \\
\hline 3 & 7 & 10 \\
\hline 5 & 31 & 196 \\
\hline 8 & 255 & 41393 \\
\hline 10 & 1023 & 2237921 \\
\hline 15 & 32767 & $1.39 * 10^{11}$ \\
\hline
\end{tabular}

Tab. 4. Design points for a product group of three products of products unused in a design point. This is represented in equations (2) and (3).

For each product usage number, there are various possibilities of product substitutions, for example, in a product group containing three products, when two of the products are selected for usage, and one is unused. In this example, either of the other two products, i.e., two different combinations, occur for this possibility of substituting the demand of the unused product. Based on this, the number of possibilities that occur for each product usage number is represented in equation (4). Table 3 presents the number of possibilities of product usage and several design points based on the size of the product group.

Table 4 presents the usage of products with the notation $U_{i}$ and product substitution with the notation $W_{i j}$ for a product group of three products.

\subsection{Product Replacement Constraint}

The next step is to make sure that the design points are valid. For this, a new variable $C D_{M}^{i}$ (Demand check of product $i$ in design point $M$ ) is introduced. The calculation for this variable is presented in equation (5). If a product i substitutes for another product $j$ in a design point, then the demand of product $j$ is added to the demand of product $i$. For a design point, the summation of demands of all products is equated to the summation of check demand. If this is true, then the design point is valid. This is to make sure that the demand for unused

$$
C D_{i}^{M}=U_{i}^{M}\left[I D_{i}+\sum_{j=1}^{N}\left(1-U_{j}^{M}\right) W_{j i}^{M} R_{i j}^{M} I D_{j}\right]
$$

products is satisfied with other products. It is represented by equation (6).

$$
\sum_{i=1}^{N} C D_{i}^{M}=\sum_{i=1}^{N} I D_{i}
$$

\subsection{MODIFIED DEMAND}

For all the valid design points, the new demand for the products in the product group is calculated by equation (7). The difference between equations (6) and (7) is the usage of the replacement factor and the substitution factor, respectively.

$$
D_{i}^{M}=U_{i}^{M}\left[I D_{i}+\sum_{j=1}^{N}\left(1-U_{j}^{M}\right) W_{j i}^{M} S_{i j}^{M} I D_{j}\right]
$$




\subsection{Cost Calculation}

The ordering quantity for the modified demand is calculated based on the economic order quantity and cost functions under the stochastic condition. The objective is to find the values of cost for a product group for each design point, as shown in equations (8) and (9).

$$
\begin{aligned}
& L C^{M}=\sum_{i=1}^{N} L C_{i}^{M} \\
& T C^{M}=\sum_{i=1}^{N} T C_{i}^{M}
\end{aligned}
$$

\section{RESUltS}

The model was programmed using Microsoft Excel and the visual basic application (VBA) language. Assumptions made for the study are listed below.

- Carrying charge for the products was $20 \%$.

- Expected length of lead-time of 3 days and the standard deviation of 0 days was considered for products for which the supplier details were missing.

\subsection{Product SUbStitution efFect}

One of the focus points for the research is to understand the product substitution effect. Here, the results are presented for both types of substitution, namely one-to-one substitution and many-to-one substitution. For this, the authors of this article used a non-sterile product group containing products that differ by colour for one-to-one substitution, and a sterile product group containing products that differ by size for many-to-one substitution.

\subsection{ONE-TO-ONE SUBSTITUTION}

The notation NSP is used to represent the nonsterile product group, where $i$ represents the product number within the product group. Since products within the product group differ based on colour, the substitution factor between these products is one. The initial details of the products in this product group are presented in Table 5.

Earlier, the authors of the article presented all the design points for a product group of three products in Table 4 . The hospital currently uses all the products within the product group, which is formed in the
Tab. 5. Initial details of products within the non-sterile product group

\begin{tabular}{|c|c|c|}
\hline & DeMAND & AVG. UNIT Cost \\
\hline $\mathrm{NSP}_{1}$ & 260 & NOK*0.172 \\
\hline $\mathrm{NSP}_{2}$ & 461 & NOK 0.127 \\
\hline $\mathrm{NSP}_{3}$ & 162 & NOK 0.133 \\
\hline
\end{tabular}

* Conversion rate as on 21.12.2019: 1 NOK $=0.11$ USD Source: https://www.xe.com/

Tab. 6. Cost when all the products in the product group are used

\begin{tabular}{|l|c|c|c|c|}
\hline \multicolumn{1}{|c|}{ DeSIGN PoINT: $(\mathbf{7}, \mathbf{1})$} & $\mathbf{N S P}_{\mathbf{1}}$ & $\mathbf{N S P}_{\mathbf{2}}$ & $\mathbf{N S P}_{\mathbf{3}}$ & TOTAL \\
\hline Demand (Units) & 260 & 461 & 162 & 883 \\
\hline Logistics Cost (NOK) & 72.43 & 82.94 & 50.28 & 205.66 \\
\hline Total Cost (NOK) & 117.13 & 141.52 & 71.84 & 330.49 \\
\hline
\end{tabular}

design point $(7,1)$. In this design point, the net logistics cost accounts to NOK 205.66 and the total cost accounts to NOK 330.49, which is presented in Table 6. Both these costs will act as a baseline for cost comparisons.

In the remaining nine design points, at least one product is unused, and another product substitutes for its demand. For the design points $(1,1),(2,1)$ and $(4,1)$, only one product is used, and in the remaining six design points, two products are used. The summary of the values of the added demand together with the related costs and the potential savings are provided in Table 7 . The usage of only product $\mathrm{NSP}_{2}$ occurring in the design point $(2,1)$ had a potential saving of $31 \%$ of the total cost. As the results suggest, the reduction of any product in this product group would result in minimum savings of $4 \%$. Therefore, at least one product should be given up in this product group to save cost.

\subsection{Many-To-one SUbStitution}

The notation $S P_{i}$ is used to represent the sterile product group, where i represents the product number within the product group. The selected product group contains two products within the product group. Table 8 presents the demand and unit cost for the products in the product group.

The products in this product group differ based on size. Consequently, the product substitution factor may or may not be one. Table 9 shows the product substitution factor for both the products in the product group.

At present, the hospital uses both products in the product group, which is formed in the design point $(3,1)$. The costs in this instance will be the reference 
Tab. 1. Cost when products are reduced from product group

\begin{tabular}{|c|c|c|c|c|c|c|c|c|c|c|c|c|c|c|c|c|}
\hline \multicolumn{2}{|c|}{ DESIGn POINT } & \multicolumn{3}{|c|}{$(1,1)$} & \multicolumn{3}{|c|}{$(2,1)$} & \multicolumn{3}{|c|}{$(3,1)$} & \multicolumn{3}{|c|}{$(3,2)$} & \multicolumn{3}{|c|}{$(4,1)$} \\
\hline \multicolumn{2}{|c|}{ Description } & \multicolumn{3}{|c|}{$\begin{array}{c}\mathrm{NSP}_{1} \text { is used. } \\
\mathrm{NSP}_{2} \& \mathrm{NSP}_{3} \text { are } \\
\text { substituted by NSP }\end{array}$} & \multicolumn{3}{|c|}{$\begin{array}{c}\mathrm{NSP}_{2} \text { is used. } \\
\mathrm{NSP}_{1} \& \mathrm{NSP}_{3} \text { are } \\
\text { substituted by } \mathrm{NSP}_{2}\end{array}$} & \multicolumn{3}{|c|}{$\begin{array}{c}\mathrm{NSP}_{1} \& \mathrm{NSP}_{2} \text { are } \\
\text { used. NSP } \\
\text { substituted by } \mathrm{NSP}_{1}\end{array}$} & \multicolumn{3}{|c|}{$\begin{array}{c}\mathrm{NSP}_{1} \& \mathrm{NSP}_{2} \text { are used. } \\
\mathrm{NSP}_{3} \text { is substituted by } \\
\mathrm{NSP}_{2}\end{array}$} & \multicolumn{3}{|c|}{$\begin{array}{c}\mathrm{NSP}_{3} \text { is used. } \\
\mathrm{NSP}_{1} \& \mathrm{NSP}_{2} \text { are } \\
\text { substituted by } \mathrm{NSP}_{3}\end{array}$} \\
\hline \multicolumn{2}{|c|}{ Product } & $\mathrm{NSP}_{1}$ & $\mathrm{NSP}_{2}$ & $\mathrm{NSP}_{3}$ & $\mathrm{NSP}_{1}$ & $\mathrm{NSP}_{2}$ & $\mathrm{NSP}_{3}$ & $\mathrm{NSP}_{1}$ & $\mathrm{NSP}_{2}$ & $\mathrm{NSP}_{3}$ & $\mathrm{NSP}_{1}$ & $\mathrm{NSP}_{2}$ & $\mathrm{NSP}_{3}$ & $\mathrm{NSP}_{1}$ & $\mathrm{NSP}_{2}$ & $\mathrm{NSP}_{3}$ \\
\hline $\begin{array}{l}\text { Initial } \\
\text { Demand }\end{array}$ & (Units) & 260 & 0 & 0 & 0 & 461 & 0 & 260 & 461 & 0 & 260 & 461 & 0 & 0 & 0 & 162 \\
\hline $\begin{array}{l}\text { Added } \\
\text { Demand }\end{array}$ & (Units) & 523 & 0 & 0 & 0 & 422 & 0 & 162 & 0 & 0 & 0 & 162 & 0 & 0 & 0 & 721 \\
\hline $\begin{array}{l}\text { Modified } \\
\text { Demand }\end{array}$ & (Units) & 883 & 0 & 0 & 0 & 883 & 0 & 422 & 461 & 0 & 260 & 623 & 0 & 0 & 0 & 883 \\
\hline $\begin{array}{l}\text { Logistics } \\
\text { Cost of } \\
\text { Products }\end{array}$ & (NOK) & 133.39 & 0.00 & 0.00 & 0.00 & 114.73 & 0.00 & 92.25 & 82.94 & 0.00 & 72.43 & 96.4 & 0.00 & 0.00 & 0.00 & 117.31 \\
\hline $\begin{array}{l}\text { Total Cost } \\
\text { of } \\
\text { Products }\end{array}$ & (NOK) & 285.19 & 0.00 & 0.00 & 0.00 & 226.94 & 0.00 & 164.8 & 141.52 & 0.00 & 117.13 & 175.56 & 0.00 & 0.00 & 0.00 & 234.82 \\
\hline $\begin{array}{l}\text { Logistics } \\
\text { Cost for } \\
\text { Product } \\
\text { Group }\end{array}$ & (NOK) & & 133.39 & & & 114.73 & & & 175.19 & & & 168.83 & & & 117.3 & \\
\hline $\begin{array}{l}\text { Total Cost } \\
\text { for } \\
\text { Product } \\
\text { Group }\end{array}$ & (NOK) & & 285.19 & & & 226.94 & & & 306.32 & & & 292.69 & & & 234.8 & \\
\hline $\begin{array}{l}\text { \% saving Lo } \\
\text { Cost }\end{array}$ & gistics & & 35.14 & & & 44.21 & & & 14.81 & & & 17.91 & & & 42.96 & \\
\hline $\begin{array}{l}\% \text { saving Tc } \\
\text { Cost }\end{array}$ & tal & & 13.71 & & & 31.33 & & & 7.31 & & & 11.44 & & & 28.95 & \\
\hline
\end{tabular}

\begin{tabular}{|c|c|c|c|c|c|c|c|c|c|c|c|c|c|}
\hline \multicolumn{2}{|c|}{ DESIGN POINT } & \multicolumn{3}{|c|}{$(5,1)$} & \multicolumn{3}{|c|}{$(5,2)$} & \multicolumn{3}{|c|}{$(6,1)$} & \multicolumn{3}{|c|}{$(6,2)$} \\
\hline \multicolumn{2}{|c|}{ Description } & \multicolumn{3}{|c|}{$\begin{array}{c}\mathrm{NSP}_{1} \& \mathrm{NSP}_{3} \text { are used. } \\
\mathrm{NSP}_{2} \text { is substituted by } \\
\mathrm{NSP}_{1}\end{array}$} & \multicolumn{3}{|c|}{$\begin{array}{c}\mathrm{NSP}_{1} \& \mathrm{NSP}_{3} \text { are used. } \\
\mathrm{NSP}_{2} \text { is substituted by } \\
\mathrm{NSP}_{3}\end{array}$} & \multicolumn{3}{|c|}{$\begin{array}{c}\mathrm{NSP}_{2} \& \mathrm{NSP}_{3} \text { are used. } \\
\mathrm{NSP}_{1} \text { is substituted by } \\
\mathrm{NSP}_{2}\end{array}$} & \multicolumn{3}{|c|}{$\begin{array}{c}\mathrm{NSP}_{2} \& \mathrm{NSP}_{3} \text { are used. } \\
\mathrm{NSP}_{1} \text { is substituted by } \\
\mathrm{NSP}_{3}\end{array}$} \\
\hline \multicolumn{2}{|c|}{ Product } & $\mathrm{NSP}_{1}$ & $\mathrm{NSP}_{2}$ & $\mathrm{NSP}_{3}$ & $\mathrm{NSP}_{1}$ & $\mathrm{NSP}_{2}$ & $\mathrm{NSP}_{3}$ & $\mathrm{NSP}_{1}$ & $\mathrm{NSP}_{2}$ & $\mathrm{NSP}_{3}$ & $\mathrm{NSP}_{1}$ & $\mathrm{NSP}_{2}$ & $\mathrm{NSP}_{3}$ \\
\hline Initial Demand & (Units) & 260 & 0 & 162 & 260 & 0 & 162 & 0 & 461 & 162 & 0 & 461 & 162 \\
\hline Added Demand & (Units) & 461 & 0 & 0 & 0 & 0 & 461 & 0 & 260 & 0 & 0 & 0 & 260 \\
\hline $\begin{array}{l}\text { Modified } \\
\text { Demand }\end{array}$ & (Units) & 721 & 0 & 162 & 260 & 0 & 623 & 0 & 721 & 162 & 0 & 461 & 422 \\
\hline $\begin{array}{l}\text { Logistics Cost of } \\
\text { Products }\end{array}$ & (NOK) & 120.54 & 0.00 & 50.28 & 72.43 & 0.00 & 98.55 & 0.00 & 103.69 & 50.28 & 0.00 & 82.94 & 81.12 \\
\hline
\end{tabular}




\begin{tabular}{|c|c|c|c|c|c|c|c|c|c|c|c|c|c|}
\hline $\begin{array}{l}\text { Total Cost of } \\
\text { Products }\end{array}$ & (NOK) & 244.49 & 0.00 & 71.84 & 117.13 & 0.00 & 181.46 & 0.00 & 195.31 & 71.84 & 0.00 & 141.52 & 137.28 \\
\hline $\begin{array}{l}\text { Logistics Cost for } \\
\text { Product Group }\end{array}$ & (NOK) & \multicolumn{3}{|c|}{170.82} & \multicolumn{3}{|c|}{170.98} & \multicolumn{3}{|c|}{153.97} & \multicolumn{3}{|c|}{164.06} \\
\hline $\begin{array}{l}\text { Total Cost for } \\
\text { Product Group }\end{array}$ & (NOK) & \multicolumn{3}{|c|}{316.33} & \multicolumn{3}{|c|}{298.59} & & \multicolumn{2}{|l|}{267.15} & & \multicolumn{2}{|l|}{278.8} \\
\hline \multicolumn{2}{|c|}{$\%$ saving Logistics Cost } & \multicolumn{3}{|c|}{16.94} & \multicolumn{3}{|c|}{16.86} & \multicolumn{3}{|c|}{25.13} & \multicolumn{3}{|c|}{20.23} \\
\hline \multicolumn{2}{|l|}{$\%$ saving Total Cost } & \multicolumn{3}{|c|}{4.29} & \multicolumn{3}{|c|}{9.65} & \multicolumn{3}{|c|}{19.17} & \multicolumn{3}{|c|}{15.64} \\
\hline
\end{tabular}

Tab. 8. Initial data of the product group

\begin{tabular}{|c|c|c|}
\hline & DEMAND & AVG. UNIT COST \\
\hline $\mathrm{SP}_{1}$ & 50 & NOK 54.95 \\
\hline $\mathrm{SP}_{2}$ & 37 & NOK 73.53 \\
\hline
\end{tabular}

Tab. 9. Substitution factor of the product group

\begin{tabular}{|c|c|c|}
\hline & $\mathbf{S P}_{1}$ & $\mathbf{S P}_{2}$ \\
\hline $\mathrm{SP}_{1}$ & 1 & 2 \\
\hline $\mathrm{SP}_{2}$ & 1 & 1 \\
\hline
\end{tabular}

Tab. 10. Cost when both products are used

\begin{tabular}{|l|c|c|c|}
\hline \multicolumn{1}{|c|}{$\begin{array}{c}\text { DESIGN PoINT: } \\
(\mathbf{3}, \mathbf{1})\end{array}$} & SP $_{1}$ & SP $_{2}$ & TOTAL \\
\hline Demand (Units) & 50 & 37 & 87 \\
\hline $\begin{array}{l}\text { Logistics Cost } \\
\text { (NOK) }\end{array}$ & 577.20 & 576.11 & 1153.31 \\
\hline Total Cost (NOK) & 3324.46 & 3296.70 & 6621.15 \\
\hline
\end{tabular}

Tab. 11. Cost when only one product is used

\begin{tabular}{|c|c|c|c|c|c|}
\hline \multicolumn{2}{|l|}{ DESIGN POINT } & \multicolumn{2}{|c|}{$(1,1)$} & \multicolumn{2}{|c|}{$(2,1)$} \\
\hline \multicolumn{2}{|l|}{ Description } & \multicolumn{2}{|c|}{$\mathrm{SP}_{1}$ is used. $\mathrm{SP}_{2}$ is substituted by $\mathrm{SP}_{1}$} & \multicolumn{2}{|c|}{$\mathrm{SP}_{2}$ is used. $\mathrm{SP}_{1}$ is substituted by $\mathrm{SP}_{2}$} \\
\hline \multicolumn{2}{|l|}{ Product } & $\mathrm{SP}_{1}$ & $\mathrm{SP}_{2}$ & $\mathrm{SP}_{1}$ & $\mathrm{SP}_{2}$ \\
\hline Initial Demand & (Units) & 50 & 0 & 0 & 37 \\
\hline Added Demand & (Units) & 74 & 0 & 0 & 50 \\
\hline Modified Demand & (Units) & 124 & 0 & 0 & 87 \\
\hline Logistics Cost of Products & (NOK) & 903.11 & 0.00 & 0.00 & 876.99 \\
\hline Total Cost of Products & (NOK) & 7716.30 & 0.00 & 0.00 & 7274.05 \\
\hline Logistics Cost for Product Group & (NOK) & & & & \\
\hline Total Cost for Product Group & (NOK) & & & & \\
\hline \multicolumn{2}{|l|}{ \% saving Logistics Cost } & \multicolumn{2}{|c|}{21.69} & \multicolumn{2}{|c|}{23.96} \\
\hline \multicolumn{2}{|l|}{$\%$ saving Total Cost } & \multicolumn{2}{|c|}{-16.54} & \multicolumn{2}{|c|}{-9.86} \\
\hline
\end{tabular}


for making the cost-saving calculation. The net logistics cost is NOK 1 153.31, and the total cost is NOK 6 621.15, which is represented in Table 10.

Since this product group contains only two products, a reduction can occur by one product generated in two design points $(1,1)$ and $(2,1)$. This reduction of the product in both design points results, in logistics cost savings amounting to more than $20 \%$ and an increase in the total cost due to the product cost. These results are presented in Table 11. Therefore, for this product group, both products should be used. This product group was chosen to demonstrate the effect of product substitution factor.

\subsection{Overall Results}

For each product group, the design point creating the lowest total cost is selected for summarisation of the results. The summary is presented in Table 12. For this hospital, the model generates a reduction of 262 items with a potential cost saving of $22.3 \%$ which is an increase of $3.80 \%$ when the inventory is optimised. The split up of the results shows that the sterile products provide cost saving of $22.97 \%$ whereas the non-sterile products generate only $13.43 \%$ in cost savings.

\section{Discussion}

In this hospital, the number of sterile products used is more than twice the number of non-sterile products used. A baseline was demonstrated to provide the potential of the reduction in the product variety for this hospital. Approximately $7 \%$ of sterile products and $21 \%$ of non-sterile products could be reduced. Therefore, more than $11 \%$ of product varieties may be reduced. Since two different types of product substitution were explored, they should be discussed individually.

For one-to-one product substitution, a non-sterile product group containing three products was

Tab. 12. Overall results

\begin{tabular}{|c|c|c|c|c|}
\hline & & StERILE & NON-STERILE & TOTAL \\
\hline \multirow{3}{*}{ Current Process } & Number of Products & 1645 & 686 & 2331 \\
\hline & Logistics Cost (NOK) & 2027437 & 1240102 & 3267540 \\
\hline & Total Cost (NOK) & 9890439 & 6334964 & 16225404 \\
\hline \multirow{6}{*}{$\begin{array}{l}\text { All products used with } \\
\text { optimised Inventory }\end{array}$} & Number of Products & 1645 & 686 & 2331 \\
\hline & $\%$ reduction in number of Products & 0.00 & 0.00 & 0.00 \\
\hline & Logistics Cost (NOK) & 663507 & 245603 & 909110 \\
\hline & $\%$ reduction in logistics Cost & 67.27 & 80.19 & 72.18 \\
\hline & Total Cost (NOK) & 7651830 & 5572990 & 13224820 \\
\hline & $\%$ reduction in total Cost & 22.63 & 12.03 & 18.49 \\
\hline \multirow{6}{*}{ Substitution Model } & Number of Products & 1524 & 545 & 2069 \\
\hline & $\%$ reduction in number of Products & 7.36 & 20.55 & 11.24 \\
\hline & Logistics Cost (NOK) & 636228 & 215468 & 851696 \\
\hline & $\%$ reduction in logistics Cost & 68.62 & 82.62 & 73.93 \\
\hline & Total Cost (NOK) & 7123596 & 5483927 & 12607523 \\
\hline & $\%$ reduction in total Cost & 27.97 & 13.43 & 22.30 \\
\hline
\end{tabular}


inspected. When all the products were used, the logistics cost was NOK 205.66, and the total cost was NOK 330.49. With the reduction of just one product, there was a drop in both the logistics costs and the total costs. The drop in the logistics cost was $14 \%-$ $25 \%$, and the drop in the total cost was $4 \%-19 \%$. This difference occurred due to the presence of product cost. The substitution of the product $N S P_{1}$ by $\mathrm{NSP}_{2}$ and the usage of $\mathrm{NSP}_{3}$ showed better results. When there was the usage of only one product, the logistics cost decreased somewhat between 35\% $44 \%$ and the total cost decreased by $13 \%-31 \%$. The usage of only $\mathrm{NSP}_{2}$ alone gave better results. Due to the variation in the cost per product of $\mathrm{NSP}_{2}$ and $\mathrm{NSP}_{3}$ in the third decimal place, $\mathrm{NSP}_{2}$ gave better results. In other words, the selection of the product with the lowest cost per product value yielded better results. This simplification was possible because the substitution factor between the products was one.

For many-to-one product substitution, a sterile product group containing two products was examined. When both products were used, the logistics cost was NOK 1 153.31, and the total cost was NOK 6 621.15. When only one product in the product group was used, the logistics cost dropped between $21 \%$ $24 \%$, whereas the total cost increased between $9 \%-$ $17 \%$. The drop in the logistics cost was possible because of pooling the demands of products. The increase in the total cost occurred due to the combination of both cost per product and the substitution factor. When $S P_{1}$ was used, the cost of product $S P_{2}$ was NOK 73.53, and the product of the substitution factor when $S P_{2}$ was substituted with $S P_{1}$, and the cost per product of $S P_{1}$ was NOK 109.90. The cost per product of $S P_{2}$ was higher than that of $S P_{1}$. Therefore, in both these instances, it resulted in a higher total cost when compared to the usage of both products. Since this product group contained only two products, the comparisons were easier. It would become more complex with the increase in the size of a product group.

The overall result shows that $262(11 \%)$ product varieties could be reduced, resulting in a cost-saving of more than NOK 3.6 million (22.3\%). According to research by Wan et al. (2012), the sales of products increase with the increase in the product variety until it reaches an optimum point and then decrease. Similarly, these results indicate that the reduction of all varieties in the product group does not yield cost reduction. The costs saved at this hospital are rather small, but on the scale of all 85 hospitals in Norway, it would result in approx. NOK 307.5 million. Thus, the study into the product variety of inventory at hospitals can bring considerable cost savings.

\section{CONCLUSIONS}

This paper investigated the influence of the product variety on hospital inventory based on the product substitution factor and the corresponding inventory cost. After the discussion of the literature, the developed model for the study was presented. This model is universal in nature and can be used in other fields, such as retail, marketing etc. The developed model contributes to the pool of literature focusing on the analysis decision-making with respect to product variety based on product attributes as well as inventory management. The influence of the substitution factor on the product variety decision was presented together with the corresponding inventory cost. The results showed a combined influence of the product substitution factor and the product unit cost.

Various additional aspects may be considered to contribute to the knowledge of the effects of the product variety on the inventory of hospitals. One of the limitations of the research presented in this article is that it does not address issues such as time taken by healthcare personnel to adapt to this change or flexibility of the hospital and other factors. Among other limitations, this research does not consider the replenishment coordination and floor space limitations. Future research may focus on having these aspects included in modelling to produce better realtime results. This research also does not account for healthcare personnel's preference for products. This aspect may prove to be a crucial factor influencing the implementation of the produced modelling results on the product variety. The incorporation of the personnel's preference into the decision-making can ensure that preferred products do not get eliminated by the decision-making framework. These are some ideas for possible future research.

\section{LITERATURE}

Borin, N., Farris, P. W., \& Freeland, J. R. (1994). A Model for Determining Retail Product Category Assortment and Shelf Space Allocation. Decision Sciences, 25(3), 359-384. doi: 10.1111/j.1540-5915.1994.tb00809.x

Erens, F., \& Verhulst, K. (1997). Architectures for product families. Computers in Industry, 33(2), 165-178.

Fujita, K., Sakaguchi, H., \& Akagi, S. (1999). Product variety deployment and its optimization under modular 
architecture and module commonalization. Paper presented at the ASME Design Engineering Technical Conferences - Design for Manufacturing, Las Vegas, Nevada.

Jayaraman, V., Srivastava, R., \& Benton, W. C. (1998). A joint optimization of product variety and ordering approach. Computers \& Operations Research, 25 (7-8), 557-566. doi:10.1016/S0305-0548(98)00010-0

Kritchanchai, D., \& Meesamut, W. (2015). Developing Inventory Management in Hospital. International Journal of Supply Chain Management, 4(2), 11-19.

Landry, S., \& Beaulieu, M. (2013). The Challenges of Hospital Supply Chain Management, from Central Stores to Nursing Units. In T. B. Denton (Ed.), Handbook of Healthcare Operations Management: Methods and Applications (pp. 465-482). New York, United States: Springer New York.

Malone, T. W. (1987). Modeling Coordination in Organizations and Markets. Management Science, 33(10), 1317-1332. doi:10.1287/mnsc.33.10.1317

McBride, R. D., \& Zufryden, F. S. (1988). An Integer Programming Approach to the Optimal Product Line Selection Problem. Marketing Science, 7(2), 126-140. doi: $10.1287 / \mathrm{mksc} .7 .2 .126$

Nishino, N., Takenaka, T., Koshiba, H., \& Kodama, K. (2014). Customer preference based optimization in selecting product/service variety. CIRP Annals - Manufacturing Technology, 63(1), 421-424. doi: 10.1016/j.cirp.2014.03.109

Ozcan, Y. A. (2005). Quantitative methods in health care management: techniques and applications (vol. 4). San Francisco, United States: John Wiley \& Sons.

Rachmania, I. N., \& Basri, M. H. (2013). Pharmaceutical inventory management issues in hospital supply chains. Management, 3(1), 1-5.

Sanchez, S. M. (2005). Work smarter, not harder: guidelines for designing simulation experiments. Paper presented at the Proceedings of the 37th conference on Winter simulation, Orlando, Florida.

Tucker, A. L., \& Edmondson, A. C. (2003). Why Hospitals Don't Learn from Failures: Organizational and Psychological Dynamics that Inhibit System Change. California Management Review, 45(2), 55-72. doi: $10.2307 / 41166165$

Varghese, V., Rossetti, M., Pohl, E., Apras, S., \& Marek, D. (2012). Applying Actual Usage Inventory Management Best Practice in a Health Care Supply Chain. International Journal of Supply Chain Management, 1(2), 1-10.

Wan, X., Evers, P. T., \& Dresner, M. E. (2012). Too much of a good thing: The impact of product variety on operations and sales performance. Journal of $\mathrm{Op}$ erations Management, 30(4), 316-324. doi:10.1016/j. jom.2011.12.002

Wang, H., Zhu, X., Wang, H., Hu, S. J., Lin, Z., \& Chen, G. (2011). Multi-objective optimization of product variety and manufacturing complexity in mixed-model assembly systems. Journal of Manufacturing Systems, 30(1), 16-27. doi:10.1016/j.jmsy.2011.03.002 